\title{
Histological and Biochemical Findings in Membranous Cataract
}

\author{
Zisis Gatzioufas $^{a}$ Cord R. Huchzermeyer ${ }^{c}$ Andrea Hasenfus ${ }^{b}$ \\ Moatasem El-Husseiny ${ }^{a}$ Berthold Seitz ${ }^{\mathrm{a}}$ \\ Departments of ${ }^{\mathrm{a}}$ Ophthalmology and ${ }^{\mathrm{b}}$ Pathology, University of Saarland, Homburg/Saar, and \\ 'Department of Ophthalmology, Friedrich Alexander University Erlangen-Nürnberg, Erlangen, Germany
}

\section{Key Words}

Membranous cataract - Epidermal growth factor ·

Fibroblast growth factor - Aqueous humor · Histology • $\alpha$-Actin

\begin{abstract}
Background: In this report we present a patient with unilateral membranous cataract and describe the histological and biochemical findings accompanying this rare condition. Methods: The patient underwent an uneventful cataract extraction. Aqueous humor $(20 \mu \mathrm{l})$ was aspirated from the anterior chamber intraoperatively and processed for fibroblast growth factor (FGF) and epidermal growth factor (EGF) using an immunoassay method (ELISA). The lens material was subjected to histological examination. Results: The patient had increased levels of FGF and EGF in the aqueous humor, as measured by ELISA. Histological examination of the lens material showed a marked fibrous metaplasia and thickening of the anterior lens capsule, while the lens epithelial cells were transformed to active myofibroblasts which generated a fibrous matrix of collagen lamellae. Unfortunately, visual function was not restored postoperatively due to underlying amblyopia. Conclusions: Our histolog-
\end{abstract}

ical and biochemical findings suggest that FGF and EGF may play a key role in the formation of membranous cataract, and therefore their impact on lens physiology should be further investigated.

Copyright $\odot 2011$ S. Karger AG, Basel

\section{Introduction}

Membranous cataract is a rare condition occurring usually soon after birth due to degeneration and liquefaction of lens fibers which are mostly absorbed. This results in the formation of anterior and posterior lens capsule opacification with prominent fibrous proliferation and epithelial metaplasia in the pupillary area. The first case of membranous cataract was described by von Ammon in 1833 [1]. There have been reported only a few cases of membranous cataract since then and its pathophysiology remains more or less obscure $[2,3]$.

This report was presented as E-poster during the XXVIIIth Congress of ESCRS, 4-8 September 2010, Paris, France.

\section{KARGER \\ Fax +41613061234 E-Mail karger@karger.ch} www.karger.com
(C) 2011 S. Karger AG, Basel 0030-3747/12/0473-0146\$38.00/0

Accessible online at: www.karger.com/ore
Zisis Gatzioufas, MD

Department of Ophthalmology, University of Saarland

Kirrberger Strasse, Building 22

DE-66424 Homburg/Saar (Germany)

Tel.+496841 162 1226, E-Mail zisis.gkatzioufas@uniklinikum-saarland.de 

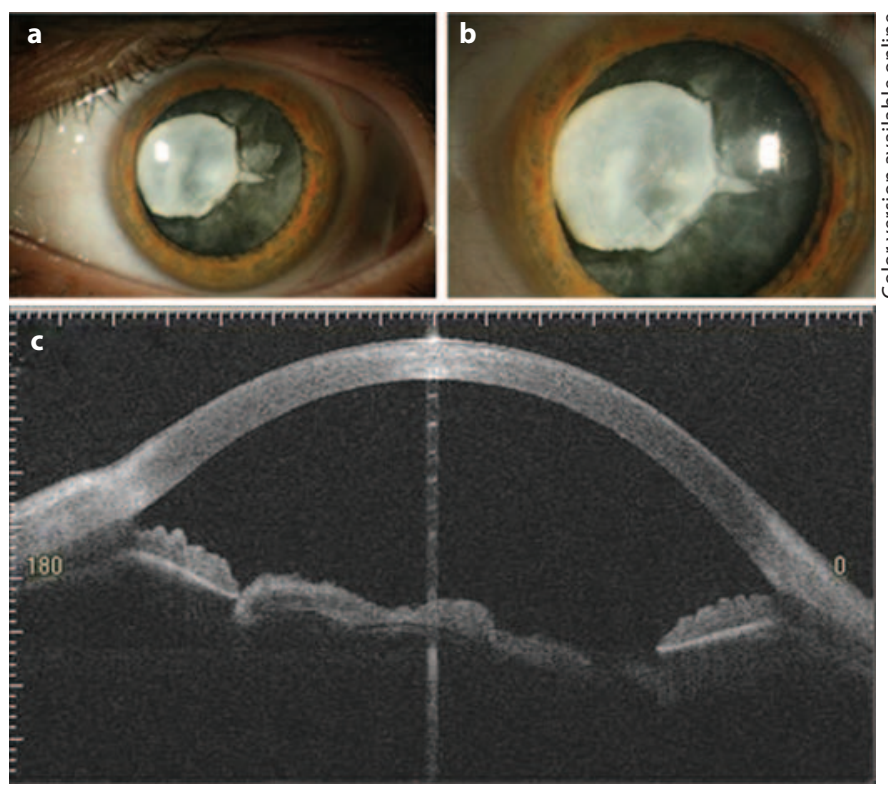

Fig. 1. Slitlamp biomicroscopy of the left eye revealed preoperatively a white mass in the pupillary area, consisting of remnants of the anterior lens capsule, degenerated lens epithelium and fibrous tissue (a, b). Optical coherence tomography of the anterior segment of the left eye revealed preoperatively a marked lesion over the anterior capsule of the lens at the level of the ciliary processes as well as marked thickening and deformation of the anterior capsule of the lens (c).

In this report we present a patient with membranous cataract who had increased levels of fibroblast growth factor (FGF) and epidermal growth factor (EGF) in the aqueous humor and discuss the possible etiopathological correlations based on this finding.

\section{Case Report}

A 39-year-old female patient with no history of intraocular surgery or trauma was referred to our hospital in November 2009 because of poor visual acuity in the left eye (OS). She reported poor visual function OS since childhood as well as a squint operation in the same eye 30 years ago. Amblyopia due to strabismus was suspected OS. Best corrected visual acuity (BCVA) was $9 / 10$ in the right eye (OD) (objective refraction: $-9.25 /-3.75 / 14^{\circ}$ ) and 2/100 OS (objective refraction: $-6.25 /-0.25 / 120^{\circ}$ ).

Slitlamp biomicroscopy revealed an opaque membrane behind the pupillary area OS (fig. 1a, b), while OD showed normal findings. Optical coherence tomography of the anterior eye segment revealed a marked lesion over the anterior capsule of the lens at the level of the ciliary processes as well as marked thickening and deformation of the lens OS (fig. 1c). Our findings were con- sistent with the diagnosis of membranous cataract OS and the decision for cataract surgery was made.

In February 2010, the patient was subjected successfully to cataract extraction OS. Although a clear-cornea phacoemulsification was planned in the first place, the aspiration of the lens material was impossible and therefore the surgeon proceeded to extracapsular cataract extraction with implantation of a polymethylmethacrylate intraocular lens in the ciliary sulcus (power $+15.0 \mathrm{dpt}$ ). Target refraction was $-3.0 \mathrm{dpt}$. The patient was treated postoperatively with dexamethasone eye drops 4 times a day, gentamycin eye drops 4 times a day and gentamycin ointment overnight. The postoperative course was uneventful.

The lens material was subjected to histological examination. Hematoxylin-eosin staining displayed a fibrous metaplasia and thickening of the anterior lens capsule (fig. 2a, b). Through the process of fibrous metaplasia the lens epithelial cells were transformed to myofibroblasts which generated a fibrous matrix of collagen lamellae. Activated myofibroblasts possess the property of contractility as demonstrated by the $\alpha$-smooth-muscle-actin signal in their cytoplasma (fig. 2c, d).

Aqueous humor $(20 \mu \mathrm{l})$ was aspirated from the anterior chamber intraoperatively and processed for FGF and EGF using an immunoassay method (ELISA), after written consent from the patient had been obtained.

ELISA demonstrated measurable levels of FGF and EGF in aqueous humor from our patient $(1.12$ and $0.91 \mathrm{ng} / \mathrm{ml}$, respectively) compared to aqueous humor samples from patients with cataracta senilis $(n=4)$, which served as a control (no traces were detectable).

Postoperative BCVA was 5/100 OS (objective refraction -3.0/ $-0.5 / 110^{\circ}$ ). Fundus examination revealed normal findings. We attributed the unsatisfactory visual outcome to underlying amblyopia OS.

\section{Discussion}

Membranous cataract is a rare condition belonging to the group of congenital cataracts [4]. Its occurrence is usually bilateral and most cases are sporadic. Characteristic features of this condition are liquefaction and resorption of degenerated lens fibers with formation of anterior and posterior capsule opacification, resembling secondary cataract after cataract surgery [4]. This results in a prominent white mass appearing in the pupillary area, consisting of remnants of the anterior lens capsule, degenerated lens epithelium and fibrous tissue.

Our patient did not have any risk factors for the development of congenital cataract (intrauterine infections, metabolic disorders, systemic diseases, genetic anomalies). Moreover, we did not detect any other ocular anomalies. Intrauterine iridocyclitis has been proposed as another potential cause of membranous cataract, but our patient reported no history of intraocular infection [5]. Slitlamp microscopy was negative for signs of uveitis (no 
Fig. 2. Histological examination of the lens material. Hematoxylin-eosin staining displayed a fibrous metaplasia and thickening of the anterior lens capsule with underlying spindle cells without any features of cell atypia $(\mathbf{a}, \mathbf{b})$. Through the process of fibrous metaplasia the lens epithelial cells have been transformed to myofibroblasts which generated a fibrous matrix of collagen lamellae. Activated myofibroblasts possess the property of contractility as demonstrated by the $\alpha$-smooth-muscleactin signal in their cytoplasma (red color staining; c, d).
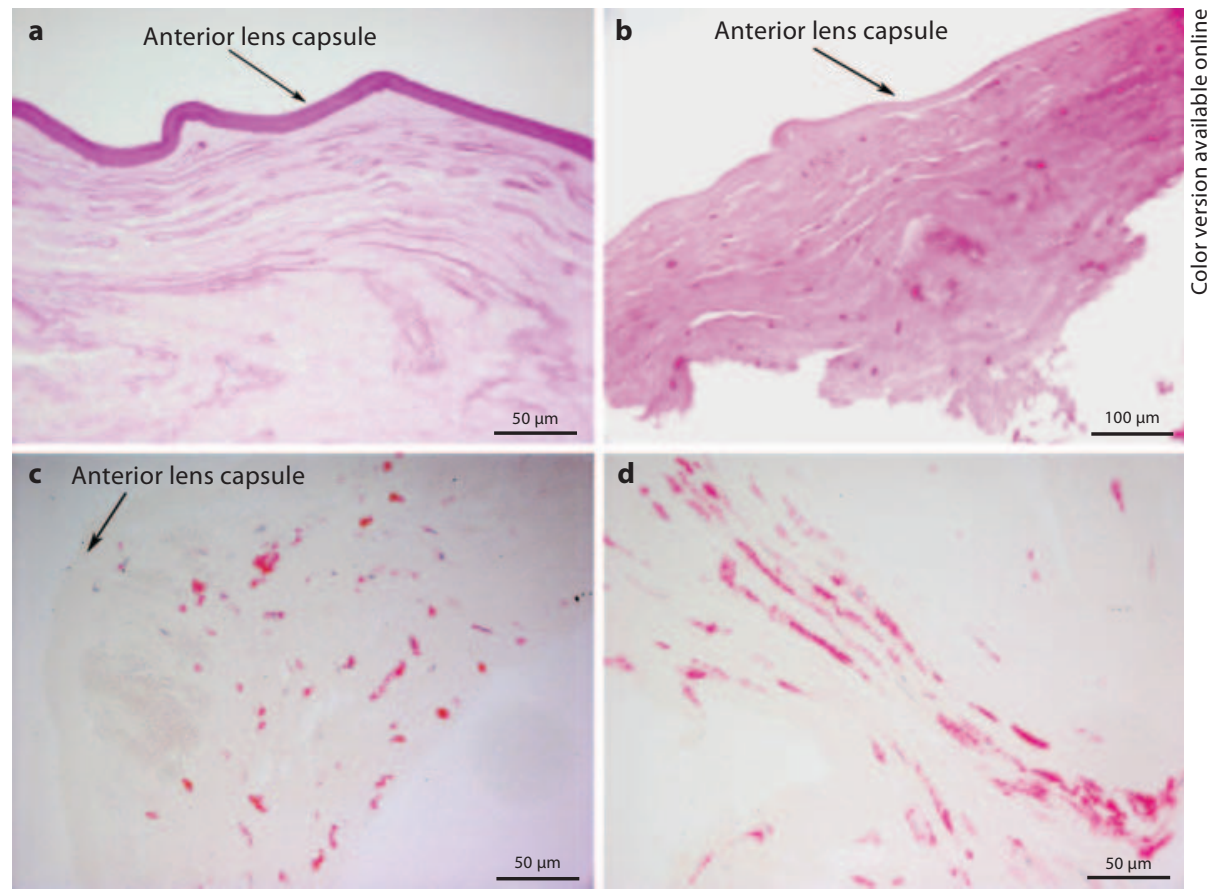

flare, no cells in anterior chamber, no synechiae, no iris atrophy). In addition, the unilateral manifestation does not support the hypothesis of a gene mutation during pregnancy.

Histological examination of the lens material showed a marked fibrous metaplasia and thickening of the anterior lens capsule with underlying spindle cells without any features of cell atypia. Moreover, the lens epithelial cells were transformed to active myofibroblasts which generated a fibrous matrix of collagen lamellae.

In order to further investigate the pathogenesis of this rare condition, we estimated the levels of FGF and EGF in the aqueous humor with the aid of an immunoassay method (ELISA). FGF and EGF promote the lens epithelial cell proliferation and induce multilayering, fibrous metaplasia and plaque formation [6, 7]. Moreover, FGF and EGF stimulate fiber differentiation in the human lens in vitro and especially FGF plays a key role in the formation of posterior capsular opacification $[8,9]$.

Our biochemical analysis documented increased levels of FGF and EGF in the aqueous humor of this patient. According to this finding and on the basis of the unilateral manifestation we hypothesize that a primary congenital anomaly such as persistent remnants of the vascular tunic of the lens, or the hyaloid artery with possible capsule rupture, or even a previous subclinical trauma resulting in a minor capsular tear, may have progressively exposed the lens epithelium to an environment of increased levels of FGF and EGF, which stimulated a marked proliferation of lenticular epithelial cells leading to the formation of an opaque lens with severe shrinkage of the lens capsule. Unfortunately, the patient refused our request for a diagnostic aspiration of aqueous humor from the right eye.

In our case a satisfying postoperative BCVA could not be achieved due to underlying pre-existing amblyopia. Nevertheless, this finding is in accordance with the clinical results published by Pong and Lai [3]. Only Heuring et al. [2] have reported significant visual improvement after cataract extraction in a patient with bilateral membranous cataract.

To the best of our knowledge this is the first reported case of membranous cataract with unilateral manifestation. Our biochemical findings suggest that the role of FGF and EGF in congenital cataract, and especially in the formation of membranous cataract, should be further investigated.

\section{Disclosure Statement}

All authors have no financial or proprietary interest to declare. 


\section{References}

1 von Ammon FA: Die angeborene Cataracta in pathologisch-anatomischer, in pathogenetischer und in operativer Hinsicht. Ein Sendschreiben des Herausgebers an den Herrn Ober-Medicinalrath Dr. Bauer in Kassel. von Ammons Z Ophthalmol 1833;3:70-99.

2 Heuring AH, Merkhaus S, Walter S, Behrens-Baumann W: Cataract surgery in cataracta membranacea. J Cataract Refract Surg 2002;28:1065-1068.

3 Pong JC, Lai J: A patient with bilateral cataracta membranacea. Ophthalmic Surg Lasers Imaging 2010;9:1-2.
4 Schlötzer-Schrehardt U, Naumann GOH Linse; in Naumann GOH (ed): Pathologie des Auges, ed 2. Berlin, Springer, 1997, pp 854-954.

5 Heydenreich A: Congenitale Iritis und Cataracta membranacea. Klin Monatsbl Augenheilkd 1954;124:573-579.

6 Kampmeier J, Baldysiak-Figiel A, de JongHesse Y, Lang GK, Lang GE: Effect of growth factors on proliferation and expression of growth factor receptors in a human lens epithelial cell line. J Cataract Refract Surg 2006; 32:510-514.
7 Majima K: Effect of epidermal growth factor upon morphological changes of human lens epithelial cells. Ophthalmologica 1998;212: 250-256.

8 Ibaraki N, Lin LR, Reddy VN: Effects of growth factors on proliferation and differentiation of human lens epithelial cells in early subculture. Invest Ophthalmol Vis Sci 1995; 36:2304-2312.

9 Mansfield KJ, Cerra A, Chamberlain CG: FGF-2 counteracts loss of TGF-beta affected cells from rat lens explants: implications for PCO (after cataract). Mol Vis 2004;10:521532 . 